\title{
Introduction of a Quality Management System for Vocational Education and Training in Slovakia
}

\author{
http://dx.doi.org/10.3991/ijep.v3i3.2733 \\ Martin Podařil ${ }^{1}$ and Roman. Hrmo ${ }^{2}$ \\ ${ }^{1}$ Constantine-the-Philosopher University, Nitra, Slovakia \\ 2 Dubnica Technology Institute, Dubnica and Váhom, Slovakia
}

\begin{abstract}
The issue of the quality of vocational education, schools, teaching and learning of students should be in the interest of all participants in the Slovakian education process. The quality of secondary school is the critical element in enhancing the attractiveness of vocational education in Slovakia. Finding an official scale that would provide such information of Slovakia is unfortunately impossible. There is no system for evaluating the quality of vocational education and training (VET) at vocational schools. There are no clearly defined criteria, rules or standards. Speaking of assessing the level of quality of vocational education on the base of existing outcomes in formal education such as monitoring, final exams or graduation exams result in one-sided evaluation and does not address the systematic coherence and complexity of this issue. Essential steps to create a functional system of evaluation of VET in Slovakia must be taken. The article describes the importance of VET which can play a central role in preparing young people for work, developing the skills of adults and responding to the labor market needs of the economy. If presents a model of quality evaluation of the vocational education and training at secondary vocational schools in Slovakia that is currently going on at many secondary vocational schools in western Slovakia and Austria. The aim of the project is to develop and apply an open, flexible and adaptable quality management system. The article does not only present indicators for evaluation, but also the way how each of them can be evaluated. The effort of this project is also to create a specialized portal with support services that provide transparent, clear and specific information from this area of interest. The introduction of the evaluation framework, the selection of the indicators that take established criteria into consideration and the assembling of the scale are therefore more than relevant and required.
\end{abstract}

Index Terms - evaluation, indicator of quality, quality, vocational education and training.

\section{INTRODUCTION}

Many countries are recognizing that good initial vocational education and training can make major contributions to make the economy competitive. Many unskilled jobs which existed in OECD countries generations ago are disappearing, either because they have been replaced by technology or because these countries cannot compete with less developed countries regarding labor costs. Instead, OECD countries need to compete regarding the quality of goods and the service they provide. That requires a well-skilled labor force, with a range of mid-level trade, as well as technical and professional skills alongside those high-level skills associated with a university educa- tion. More often than not, those skills are delivered through vocational programs [2].

Vocational education and training (VET) can play a central role in preparing young people for work, developing skills of adults, and responding to the labor market needs of the economy. It means to start building a foundation of basic and transferable skills into vocational qualifications, to reflect the chances of a world career and personal development rather than one job for life. That means a renewal of the career guidance profession so as to deliver active guidance for all young leaders, wellinformed by knowledge of the labor market and vocational opportunities as well as academic pathways. It means ensuring that teachers and trainers in VET programs have up-to-date industry experience. [5]

Initial VET is designed to fill the gap providing the needed skills, and research has shown that such an education can yield good economic returns from the public investment involved. Among general academic skills, numeracy and literacy are of increasing importance in the labor market, and weaknesses in these fields are very common to those in vocational programs. VET programs need to give a sufficient weighting to these skills and students should be systematically assessed at the point of entry to vocational programs as to ensure a basic minimum of skills and to identify the needed support. [1]

For the right running of the country it is essential that the economic growth will not be behind that of other countries in Europe. Slovakia does not have an effort to stay behind on the current economic position, but starts to keep up with the most advanced states of the European Union in the shortest possible time. It is important to educate the graduates to be able to work not only at the production lines of companies, but also to be able to manage these companies. An important and essential step towards meeting this objective is an increased number of secondary vocational schools in high quality. The question is how it is possible to know for employers and applicants which schools are up to standard of the required classification. There is not created top chart for quality of the secondary schools in Slovakia. There is only a quality comparison of the universities. The awareness to solve the issue of evaluating the quality of vocational education and the creation of the Quality Management System for Vocational Education and Training are stimulated by impulse, need, urgency and pressure of the general public as well as the schools themselves. [3] 


\section{VOCATIONAL EDUCATION AND TRAINING}

On $22^{\text {nd }}$ September, 2005 in Copenhagen (OECD 2005) the chief civil servants of the education ministries from across the OECD opened a two-day discussion. Their agenda was wide-ranging. They had been asked to identify their most important policy priority in education in the upcoming years. The answer they gave surprised many, for it was neither schools nor universities, but in fact, vocational education and training (VET). Three factors stand out as reasons for the growing interest of policy makers in VET: Economics, strains in the system and previous neglect.

\section{A. Economics}

Since OECD countries can not compete with less developed countries regarding labor costs, they need to compete in terms of the quality of goods and the services they provide. That means highly skilled labor force, as well as technical and professional skills alongside those high-level skills associated with university education. [2]

\section{B. Strains}

There are strains put on the VET system. One of them is the lack of workplace training places and another is the lack of trainers. In some countries the rapid expansion of tertiary education has undermined school-based VET. For example in the United States the new term of ,career and technical education“ has replaced „vocational education and training" to reflect an orientation towards a career rather than a single occupation. [6]

\section{VET has been neglected.}

Challenging issues like how to go about teaching practical skills or the rapid expansion of tertiary programs have received limited attention. The perceived low status of VET has therefore also been a barrier against engagement in the sector and how it has been viewed analytically. [4]

Vocational education and training (VET) includes education and training programs designed for a particular job or type of job. It normally involves practical training as well as learning or relevant theories. It is distinct from (academic) education - for example in mathematics which is relevant to a wide range of jobs. Education and training for some high level professions such as medicine and law meet the definition even though they are not normally described as VET.

Initial VET includes programs mainly designed for and used by young people (under 30) at the beginning of their career and commonly before entering the labor market. It includes many upper secondary and tertiary programs.

Continuing VET are all other sorts of VET, including enterprise training of employees and training provided for those who have lost their job. [6]

\section{CHARACTERISTICS AND OBJECTIVES OF THE PROJECT}

The project compares individual approaches and recent trends in the quality management in vocational education in Slovakia and abroad and is aimed at drafting the model for assessment of the quality of education at secondary vocational schools and its verification at selected schools. The main objective of this project is to establish assumptions for the creation of an independent and institutional system. This system should meet the criteria of openness, flexibility, adaptability and should also give us a true picture of the quality of vocational schools, the so-called quality mark. It also needs to be stated that the project objective is to establish a specialized portal with support services that will provide sufficiently clear, profound and specific information to the potentially interested persons in the field of quality management in vocational education.

In this connection, two main objectives for implementation are:

a) Proposal and verification of the system of quality management and certification of educational institutions and lifelong learning programs at selected vocational schools.

b) Development of a common reference framework for the evaluation of the quality of vocational education and training in accordance with current national and EU legislation.

This project is progressing and is based on the methodology of ENQA-VET (CAQF model) - the European Network for Quality Assessment of Vocational Education and Training.

\section{PHASES OF THE PROJECT}

The project consists of three closely related phases:

\section{A. Analysis of current status and application of existing approaches and quality management systems in vocational education and training}

Objectives: to analyze the advantages and disadvantages of possible approaches to quality management in the field of vocational education and training and to develop a set of recommendations for the development of models for the evaluation of the quality of vocational education and training at secondary vocational schools in Slovakia-including the quality indicators in accordance with international standards and the needs of each participation in vocational education, so as to create a terminological dictionary in the field of vocational education and training.

\section{B. Development of a model for quality management in vocational education including the first verification}

Objectives: to design a model based on criteria and indicators for the evaluation of the quality in vocational education and training, to design a methodology including the proposal of tools for supporting the implementation of proposed models within the first verification at selected vocational schools.

C. Creation of educational and training programs for teachers at secondary vocational schools and the creation of a portal focused on the benchmarking of vocational schools

Objectives: to create a program especially focused on the group of teachers at vocational schools with the future focus on quality management at educational institutions, to run a specialized portal with interactive and support services such as thematic discussion groups, forums, video presentations, databases etc. 


\section{INDICATORS FOR QUALITY EVALUATION AT SECONDARY VOCATIONAL SCHOOLS}

Objective within the project is to create a model of quality evaluation of vocational education and training at secondary vocational schools in Slovakia. One of the first steps towards establishing a functioning model was to determine the basic indicators and their evaluation system. For the effective evaluation of the need to designate a number of indicators to them, the existing indicators were not enough. For this reason, we proposed these indicators.

\section{A. The results of students}

This indicator is focusing on the study results of students which are objectively measurable. It is just seven years ago that the Ministry of Education of the Slovak Republic accepted compulsory external parts of the leaving exam. The tests are the same for every type of school and therefore we can consider them as objective.

At particular schools we will look at the number of tested students in a certain subject (mathematics, Slovak language and literature), calculate the average success of each school subject and the difference of school success to the national average in a certain school subject.

The number of students is defined as the number of all vocational school students in the Slovak Republic who are tested in that required year. An average school is given by the average of success of all tested students in a certain school and subject. The difference to the national average expresses if the difference of the average success of a school is higher than the national average. A negative number means that the average success of school is lower than the national average.

A successful school has high standards and regularly monitors the performances and requirements for the success. The assessment of achieved educational outcomes is a sign of added its value. Successful school fully realizes the outputs, results of own work mainly following the conditions of education, economical sources and the input state.

The mentioned indicators will be given their adequate importance. Based on this information, the secondary schools will the concept on results of their students. The value of the importance will be counted over for every participating school. After evaluation the schools will be lined up according to achieved score.

\section{B. The rate of methods utilization in evaluation, testing and classification}

Pedagogical diagnostics deals with objective findings, as assessment and the evaluation of the external and internal conditions and courses. It focuses on the results of the educational process as well. The school evaluation is mostly a tool for the parents too. It ensures the information on the success of their children at school.

The quality of schools in Slovakia has recently been judged from the student's evaluation point of view. Therefore we give attention to the following fields of student evaluation regarding the evaluation of the school quality:

- Forms and methods of testing. Forms of testing: evaluation of new trends (projects, case studies, combination of the forms). Methods of testing: writing, oral testing, combination of both.
- Forms and methods of student's evaluation - utilization of new trends (individual oral evaluation, making the tasks, student - partner of teacher in the evaluation etc.), possibilities to give the feedback by students to the teacher, utilization of the criteria and standards of testing).

- Classification of students - using of expanded, verified and individualized evaluation, oral evaluation and evaluation based on achiever points, evaluation based on negative points.

- Effect of testing on the state of mind of the students using of stressful ways of student testing (for example: oral testing in front of all schoolmates).

- Effect of evaluation on the motivation of the students

Within the indicator of using methods in evaluation, testing and classification we chose three levels:

- Standard level: using of formative evaluation in the teaching process.

- Minimum level: consists of the methods of evaluation, testing and classification which follow legal recommendations and methodological guidelines.

- Maximum level: percentage of students in the evaluation, self-evaluation.

To gain the data we will use the method of observing which has the form of observing/audit notation. The gained data we will evaluate regarding the levels which will be assigned number points. The level will be evaluated regarding the appearance $(3=$ maximum, $2=$ standard, 1 minimum, $0=$ does not meet any requirement).

\section{Using of teaching methods and styles}

One of the important facts for good quality work of a teacher is their professional skill, experiences, motivation and taste to work properly, as well as enthusiasm. A teacher need not only know standards of the teaching process, but mainly they need to follow them. There are certain attributes that a teacher is not able to decide about such as length of the lesson or schedule. There are many ways of how to manage the teaching process.

In determining the evaluation indicator "teaching methods and styles" we identified methods based on the nature of students' cognitive activities as the most important ones. From the total significance of the indicator, we assigned significance to each method (Table I). In determining the method significance we took consideration on how teachers lead their students to independent thinking, to the creation of new and innovative solutions and to independent and creative cooperation.

Gaining the data will be done according to the observation and analysis of documents.

\section{Quality of a physical environment}

In our suggestion for evaluation we also focused on an environment which is directly connected with educational processes. It is the environment in which students spend most of their time during their time at school. We divided the physical environment into two main parts and focused on their most important components.

\section{1) Climate at school}

It includes the stability of a school (control of the tutors, clear formulation of requirements, rigorous criteria for 
TABLE I.

\begin{tabular}{|l|l|c|}
\hline \multicolumn{1}{|c|}{ Order } & \multicolumn{1}{|c|}{ Teaching method } & $\begin{array}{c}\text { Assigned importance } \\
\text { in \%o }\end{array}$ \\
\hline 1. & Problem explanation method & 24 \\
\hline 2. & Heuristic method & 21 \\
\hline 3. & Research method & 17 \\
\hline 4. & Reproductive method & 5 \\
\hline 5. & Information - perceptive method & 3 \\
\hline Order & Teaching styles & $\begin{array}{c}\text { Assigned importance } \\
\text { in \% }\end{array}$ \\
\hline 1. & Mass teaching & 10 \\
\hline 2. & Group teaching & 10 \\
\hline 3. & Individual teaching & $\sum=100 \%$ \\
\hline & & \\
\hline
\end{tabular}

evaluation, realistic visions and school's activities), support and leadership for tutors from principals (constructive criticism aimed at the prosperity of a school and its teachers, motivation of teachers, leading by example), teacher's engagement (teacher's initiative, collaboration with fellow colleagues, willingness to follow school's vision, effort to lead students to success, creating of an environment of trust), teacher's frustrations (too much bureaucracy and paper work viewed as unnecessary by teachers, bad relationships between colleagues) and good relationships among school staff (solid friendship between colleagues, conflicts are solved effectively and professionally, relationships exist outside working environment)

2) Climate in the classroom

It includes support (creating positive attitudes towards learning, teacher's support and encouragement to explore, eliminating fear of making mistakes and learning from the outcomes of student's endeavors), order (purposeful boundaries and rules for learners' behavior at school and consistency in their implantation), involvement (opportunities for communication such as asking questions freely and confidently, facilitating activities during which students can practice decision making), standards (clearly defined set of norms for achievement, however, not only in terms of performance but in terms of personal attitudes), purpose (emphasizes aims of education, gives clear purpose for activities or topics; "Knowing Why" is the most important aspect for student's motivation at school), responsibility (student feels personally responsible for their own learning (managing of tasks, involvement in school's work, achieving success), promoting interest in education ( this is the main agenda for teachers. Teachers can strive to make their subjects more popular by accentuating practical applications, but it depends on the motivation of the students who need to have interest in themselves as well as in their work), expecting success (success is openly expected from a student as well as their ability to adhere to their responsibilities and potentials for success in the future), fairness (absence of favoritism, double standards and clear connection between work well done and reward for it), safety (absence of violent physical or psychological behaviors and other stressful factors, educating students how to deal with these situations), environment (clean environment, stimulating and comfortable for the service users).

Data obtained are compared with outcomes from other schools by percentage $(3=100-90$ percentage, $2=89,99$
-80 percentage, $1=79,99-70$ percentage and $0=69,99$ 0 percentage)

\section{E. Partnerships and resources}

The indicator of partnerships and resources is an important element determining the orientation and aim of a vocational school. An efficient cooperation between a school and its partner can lead to a positive rating of its educational process. Partnerships of a school can also influence the cash-flow which can be capitalized by the school. Thus, we merged these two fields into one unit while each of the components retains its substance. The school should represent itself especially in the field of education, technical support and cooperation in the field of a research. The aforementioned indicator influences activities of successful academics at such a school. Technical possibilities can be provided by a strong partner of the school which can bring not only technical and material possibilities but also prestige and a dissemination of the quality of the school connected with it.

The following points were suggested for correct point evaluation of the indicator "partnerships" and resources.

1) Partnerships:

- Identification of school partners (educational institutions, science and research, industry, etc.)

- Length of the partnership continuation (arising from the conditions).

- Plans and schedule of the partnership - long-term, short-term, systematic, etc.

- Number of partnerships and their quality and accomplishment.

- Contractual partnerships (transition from school theory to practice).

- Requirements and commitments following from the partnerships.

- Propagation and publicity of partnership.

- Technical and practical possibilities resulting from the partnership.

- Material resources utilized on the basis of the partnership.

- Further education following from the partnership.

- Opportunities of internships.

- Organization of seminars, conferences, educational days with partner company.

2) Resources

- Number of financial resources of the school (definition of resources, duration of drawing, amount of funds, etc.).

- Economical management of the school.

- Additional resources.

- Purpose of utilization of additional resources (school modernization, wages, student activities, etc.).

- Efficiency of utilization of resources and additional resources.

- Existence of a control mechanism of resource utilization.

- Savings of the school.

- Success rate of applied projects. 
- Drawing of financial resources from grants and projects.

- Non-financial resources and their utilization.

A complex of these attributes should assure a successful evaluation of the indicator of partnerships and resources. It is necessary to add that these points are closely related to the evaluation of this indicator which guarantees homogeneity of the evaluation. All of the points were chosen so that the groups are not influenced by other factors and are discrete.

We chose three levels of evaluation for the presented indicator - partnerships - according to the available possibilities. It is important for us that each vocational school is involved in a certain type of partnership within its qualification in a particular field.

- Minimum level - At least one partnership with any type of company.

- Standard level - from one up to three partnerships, efficient exploitation of the partnership between a school and a company, mutual visits of company eployees, use of benefits arising from the partnership.

- Maximum level - more than three partnerships with companies (businesses), premium relationships with partners of the school (excursions, visits, benefits arising from the partnership, seminars, invited lecturers), long-term cooperation, effort in exploitation of capabilities of the partnership at the highest rate possible.

A questionnaire technique will be utilized to collect information. The obtained data will be evaluated according to the levels. Each level will be awarded a point value: $3=$ maximum, $2=$ standard, $1=$ minimum, $0=$ does not meet any of the criteria.

The indicator "resources" will be evaluated with the help of evaluation forms. Each of the directors assigns particular statements in the form values 0 or 1 according to whether a school satisfies a particular criterion (1 if it satisfies, otherwise 0 ). The total sum of points will be further averaged and the final value from interval $<0,1>$ will be expressed.

The final three indicators that we started are not finalized yet in the current phase of the project progression. Therefore, we decided not to include them in this study. We only present their brief characterizations as follows.

\section{F. Quality of psycho-social environment}

This indicator evaluates the quality of life of children and youths in their educational environment and the quality of living of teachers in Slovakia. We think that special attention should be paid to the quality of living of teachers and to their job satisfaction.

Since we consider a teacher to be a very important element affecting the quality of education and professional preparation at high schools, we will realize a survey which aims at the determination of an overall quality of living and of the job satisfaction of high school teachers and compare results with respect to age and gender.

\section{G. Fraction of graduates continuing their studies}

The evaluation of this indicator should not be based only on an analysis of the number of graduates of a high school who continue in further study, but also the quality of the graduates' school should be considered.

\section{H. Fraction of graduates employed in practice}

This indicator should take into account the percentage of graduates of a high school who even after three months after graduation are not employed and are registered as unemployed at job centers.

\section{PlanNED OUTPUTS OF THE PROJECT}

Within the solution of the project there have been established several footholds, resulting in realized project outcomes, such as:

1. Terminological vocabulary - In the area of the quality management of vocational education and training

2. Creation of tools to support the implementation of the model of evaluation for the quality of vocational education and training at selected secondary schools in Slovakia.

3. Methodology to evaluate the set of indicators - the methodology for evaluation of vocational education and training

4. Education programs - design and development of education programs according to international standards

\section{EXPECTED CONTRIBUTIONS OF THE PROJECT}

Considering the diversity of educational institutions, and the wide range of educational activities of different quality, as well as the fact that at present there is no developed comprehensive concept of quality management in vocational education and training (VET) in the context of lifelong learning, the major benefit of this project is the creation and verification of a unified system of project management based on the results of so-called best practice at home and abroad in accordance with trends and international standards in the area of VET. The results will then be linked to the conceptual and developed documents in Slovakia and the European Union.

The impact of the realized project activities is expected for specific groups such as Slovak citizens, employers, public administration, but mainly on educational institutions and participants in VET. Secondary vocational schools will be stabilized as players on the labor market and will provide required educational programs with a standard quality level. They will flexibly respond to evolving labor market needs and adapt their educational programs to the qualification standards described in the national system of qualifications. They will allow the flow between systems of education which will have an impact on the attractiveness of VET as a part of lifelong learning.

\section{CONCLUSION}

The project aim is to address the system of quality management in vocational education and to prepare a manual which can help high schools to create their own evaluation tools for measuring the quality of their educational environment. In compliance with the fixed schedule of the project, the analysis of a current state of research problem was realized, the proposal of the quality evaluation model of VET was developed including indicators and terminological vocabulary for the area of quality in VET. The project is configured to achieve effective and efficient tools for quality evaluation at secondary voca- 
PAPER

INTRODUCTION OF A QUALITY MANAGEMENT SYSTEM FOR VOCATIONAL EDUCATION AND TRAINING IN SLOVAKIA

tional schools in Slovakia, which would ultimately give us answers related to the education process at secondary schools.

The project is currently in the phase where we are able to name some of the chosen indicators of quality. After assignment of importance to particular indicators and subindicators, we will continue with their verification in practice.

\section{REFERENCES}

[1] Eurostat (2002). European Social Statistics, Continuing Vocational Training Survey (CVTS2), Luxemburg

[2] Field, S., Kuczera, M. et al (2010) Learning for Jobs. Synthetic report of the OECD Reviews of Vocational Education and Training. OECD.

[3] Hrmo, R. - Krpálková Krelová, K. 2009. Improvement of pedagogical skills of training teachers. In : Problémy Profesiologii. 2009. Č. 2, s. 189 - 197. ISSN 1895-197X.

[4] Ludvig, V., Pfeiffer, F. (2005) Abschreibungsraten allgemeiner und beruflicher Ausbildungsinhalte, ZEW Discussion Paper.
[5] OECD 2009. Education at the Glance. OECD Paris.

[6] OECD 2010. Designing Local Skill Strategies. OECD, Paris

\section{AUTHORS}

M. Podařil is with the Faculty of Education, Constantine-the-Philosopher University, Nitra, Slovakia (e-mail: podaril.martin@gmail.com).

R. Hrmo, is with Institute of Didactics, Technology and Educational Technology, Dubnica Technology Institute, Dubnica and Váhom, Slovakia (e-mail: roman.hrmo@gmail.com).

This article is an extended and modified version of a paper presented at the EDUCON2013 conference held at Technische Universität Berlin, Berlin, Germany from March 13-15, 2013. It is supported by the project KEGA No. 026STU-4/2011 - Quality Evaluation Model of Vocational Education and Training at Secondary Vocational Schools in Slovakia. Submitted 04 May 2013. Published as re-submitted by the authors 26 June 2013. 